\title{
A Cross-Sectional Evaluation of EFL Students' Critical Thinking Dispositions in Digital Learning
}

\author{
Yueer Wei \\ School of International Studies \\ Zhejiang University \\ Hangzhou, China \\ weiyueer@zju.edu.cn
}

\author{
Jie $\mathrm{Hu}^{*}$ \\ School of International Studies \\ Zhejiang University \\ Hangzhou, China \\ huj@zju.edu.cn \\ *Corresponding author
}

\begin{abstract}
EFL college students acquire knowledge in the digital learning environment. Fostering critical thinking dispositions in digital learning is of great importance. This crosssectional study aims to explore the impact of digital learning on EFL college students' critical thinking dispositions. This study invites 64 EFL students from $Z$ University and conducts the Chinese version of Critical Thinking Disposition Inventory (CTDI-CV) and semi-interviews for measurements. It finds out that digital learning impacts EFL students' critical thinking dispositions although it is not the only contributor. EFL students' overall critical thinking dispositions as well as truth-seeking, analyticity and self-confidence increase obviously throughout four college years. But it cannot be neglected that truth-seeking and systematicity are still relatively weaker even in the time of graduation. This study not only points out the change of EFL college students' critical thinking dispositions but also offers suggestions for the higher education.
\end{abstract}

Keywords—connectivism, critical thinking dispositions; digital learning; EFL learners

\section{INTRODUCTION}

Critical thinking is recognized as one of the most important competences individuals should acquire in modern society and a high priority in the higher education [1]. It is an objectiveoriented and self-regulatory judgment targeting at problemsolving or decision-making.

Critical thinking disposition, together with critical thinking skills, is a complementary part of critical thinking. It is defined as a consistent internal willingness, attitude or motivation to decision-making and problem-solving [1]. A critical thinker is not a person who merely knows critical thinking skills but a person who knows the skills and has a strong disposition towards critical thinking. Critical thinking disposition is therefore an indispensable requirement for a genuine critical thinker. Previous research investigate students' critical thinking dispositions and try to find out proper methodologies for fostering the positive critical thinking disposition [2]. Crosssectional or longitudinal study was conducted to compare the critical thinking disposition among students from different grades or different phases of the same group of students so as to prove the impact of the higher education on fostering critical thinking disposition [3].
Connectivism, which regards learning as a process of connection and network formulation, is a proposed learning theory for digital learning [4]. Based on connectivism, digital learning is described as a type of learning which is assisted by digital technologies, such as smart phones and the Internet. Massive open online courses (MOOCs) are prominent representatives which attract more and more attention [5]. However, compassing technologies in digital learning is not enough. Some studies point out that the human factor plays an important role. For instance, based on the theory of connectivism, educators take an essential role in digital learning. According to a concept about human's mind and behaviors, learners' behaviors in the online learning environment greatly impact the design of MOOCs [6]. Accordingly, as a concept about human's mind and behaviors, the critical thinking disposition deserves attention.

There are several studies investigating the relationship between the digital technology and students' critical thinking dispositions. Some of them draw attention to the cultivation of pre-service teachers. For example, in a research context of the exploration of the relationship between media literacy levels and critical thinking dispositions of pre-service teachers, it is found that their critical thinking dispositions have a medium positive relationship with media literacy but a low positive relationship with media addiction, and this relationship also differs along with gender and major. [7]. Regarding with the impact of online communities on the critical thinking disposition, the impact of the online communities is explored to be weak, which only affects the target participants' selfconfidence and open-mindedness. In the context of Wechatassisted learning environment, the critical thinking disposition is found to be promoted with the help of the problem-based learning method. Besides, a cross-sectional study is conducted among distance education students, exploring the relationship between their learning styles and their critical thinking dispositions. This study shows that distance education students' critical thinking dispositions are at a low level. The sub-scales of analyticity and open-minded ness are relatively good. Besides, females perform better than males in critical thinking dispositions [3].

However, few studies have explored the change of EFL college students' critical thinking disposition across their undergraduate education in the condition of the digital learning. 
Therefore, this study wants to fill the research gap, finding out to what extent digital learning influences EFL students' critical thinking dispositions over their college life.

This study makes a comparison of critical thinking dispositions between EFL freshmen and EFL seniors, figuring out the changes in order to explore the impact digital learning has on EFL college students' critical thinking dispositions and make some suggestions on digital learning and the cultivation of the critical thinking disposition in the higher education. The Chinese version of Critical Thinking Disposition Inventory (CTDI-CV) created by Peng and fellow researchers is adopted for measurement [8].

\section{Methodology}

\section{A. Participants}

Sixty-three EFL students participated in the study. Thirtytwo of them were seniors, whose ages ranging from 18 to 19 years, and thirty-one of them were freshmen whose ages ranging from 22 to 23 years. All of them came from Z University in the Southeast China. This university supports the digital learning courses in the form of MOOCs and online learning platforms. EFL majors in this university learn some of their main courses on online learning platforms such as Blackboard and Moodle.

\section{B. Measurements}

1) The Chinese Version of Critical Thinking Disposition

This study adopted the Chinese version of Critical Thinking Disposition (CTDI-CV). The origin version of CTDI-CV is California Critical Thinking Disposition (CCTDI), which is invented according to the characteristics of ideal critical thinkers described by the Delph experts. Considering that its reliability and validity decrease when measuring Chinese students' critical thinking dispositions due to culture differences between the U.S.A. and China, CTDI-CV makes some revisions to keep cultural sensitivity to Chinese students.

CTDI-CV is a 70-item, 6-point Likert scale test with 7 subscales including truth-seeking, open-mindedness, analyticity, systematicity, self-confidence, inquisitiveness and maturity. For each item, 6-point Likert scale includes statements as "strongly disagree, disagree, slightly disagree, slightly agree, agree and strongly agree". Participants are supposed to pick out one of them based on their own experience. The overall score of the CTDI-CV ranges from 70 to 420 . Getting a score of 210 or less means possessing a negative critical thinking disposition; getting a score of 280 or more means possessing a positive critical thinking disposition and getting a score which ranges from 211 to 279 means possessing a middle level disposition towards critical thinking. As for each characteristic, the score ranges from 10 to 60 . Getting 30 or less scores means a negative attitude towards the characteristic; getting a score ranging from 31 to 40 means an ambiguous attitude towards the characteristic; and getting 40 or more score means a positive attitude towards the characteristic.

All the items in this study were arranged in a random order in case that the participants get hints from well-ordered items.
In this study, Cronbach Alpha Reliability Coefficient of the CTDI-CV was 0.86 in total, and Cronbach Alpha Reliability Coefficient of the subscales ranged from 0.45 to 0.74 .

\section{2) Interviews}

In order to investigate whether and how digital learning impacts EFL students' critical thinking disposition, semistructured interviews were conducted after seniors finishing the questionnaires. Fifteen senior EFL majors were randomly invited to have interviews.

\section{Data collection and data analysis}

Data were collected twice. The first collection was at the beginning of the first semester of the whole school year when freshmen just began their college life. The second collection was seven months later, at the end of the second semester of the whole school year when seniors was about to graduate. In the first collection, 31 freshmen majoring in English language finished the CTDI-CV anonymously in a classroom. In the second collection, 32 seniors majoring in English language finished the CTDI-CV anonymously in the same classroom. In order to keep the validity of the test, all the participants finished the questionnaire under guidance. They were told to make choices based on their real personal experience. All these questionnaires were valid. Overall and subscale scores were collected and they were analyzed by SPSS 24.0. A descriptive analysis and an independent sample $t$-test were conducted for comparing differences of critical thinking dispositions between freshmen and seniors.

\section{RESULTS}

The present study tends to evaluate EFL students' critical thinking dispositions in digital learning and poses two questions. The first question is whether digital learning influences EFL students' critical thinking dispositions. And the second question is that if it has influences, how students' critical thinking dispositions change.

Firstly, a descriptive analysis was conducted to describe the status quo of EFL students' critical thinking dispositions. The CTDI-CV interpretative guidelines were used to guide the analysis. Details are shown in Table 1.

As seen in Table 1, the mean of seniors' overall scores was 302.66. The maximum score was 366 and the minimum score was 239. All of them were higher than $210.83 .25 \%$ of them got scores higher than 280, even two students of whom got a score more than 350 . And none of them got scores lower than 210. What mentioned above showed that seniors had a positive inclination towards critical thinking in general. As for freshmen, the mean of their overall scores was 286.35. The maximum score was 342 and the minimum score was 231. Although these scores were lower than the scores of seniors', all of them were higher than 210. Besides, $64.52 \%$ of the freshmen got scores higher than 280. What mentioned above indicates that freshmen also had a positive inclination towards critical thinking in general, although the inclination was weaker than the seniors'. A further investigation to subscales, presented in Table 2, showed that both freshmen and seniors got the highest score in inquisitiveness, which indicates the most positive inclination among these seven subscales. And both freshmen 
and seniors got the lowest score in truth-seeking. As for seniors the mean of truth-seeking was the only one which was lower than 39, indicating an ambiguous attitude, while as for freshmen, the means of truth-seeking, systematicity and selfconfidence were lower than 39, showing that their inclination to these three characteristics were ambiguous.

The analysis of descriptive statistics presented some differences of critical thinking dispositions between freshmen and seniors. In order to figure out whether the difference was significant or not, an independent sample $t$-test was conducted. Table 2 shows the results.

Students' critical thinking dispositions in the study were observed to be statistically different in several dimensions including truth-seeking ( $\mathrm{t}(61)=2.48, p<0.05)$, analyticity $(\mathrm{t}$ $(61)=2.40, p<0.05)$, self-confidence $(\mathrm{t}(61)=2.19, p<0.05)$, as well as the overall score $(\mathrm{t}(61)=2.25, p<0.05)$. In all the dimensions mentioned above, the average scores of seniors were significantly higher than those of freshmen.

In order to verify the impact of digital learning, semistructured interviews for seniors were conducted. Fifteen seniors were requested to answer two questions: Does the digital learning environment makes any influence on you? What are the influences in detail? All of them thought digital learning had influences on them and these influences included both positive and negative factors. Twelve of them recognized that the positive factors outweighed the negative ones.

\section{DISCUSSION}

This study explores college EFL students' critical thinking dispositions in the digital learning environment. Combining the semi-structured interviews with the statistical analysis, it is found that students become more positive towards critical thinking across their four-year college life in the digital learning environment. Compared with freshmen, seniors get a higher average score in each subscale. This is highly related to the characteristics of digital learning. First, the digital learning is convenient, for it breaks the temporal and the spatial limitations for knowledge acquisition. Second, knowledge provided at digital learning platforms is attractive, for it is more abundant, accessible and vivid than that provided in the traditional courses. Third, college students are immersed in electronic products and digital learning platforms in their daily life. College EFL students are satisfied with the College English Education in the Massive Open Online Courses (MOOCs) [9]. Due to these three characteristics, digital learning promotes critical thinking dispositions. For example, it greatly arises students' curiosity and desire for learning. The more knowledge students get, the more confident they feel when making decisions. Thus, students' inquisitiveness and self-confidence are fostered effectively.

In this study, truth-seeking, analyticity and systematicity are found to be obviously improved throughout college years in the digital learning environment. It seems that shortcomings of digital learning may hinder the development of these subscales. Distinguishing true and meaningful knowledge from fake and useless information is a challenge. Besides, self-regulation easily decreases because of high degree of addiction to digital platforms. Students are easily distracted by the information which is interesting but unrelated to their learning objectives. However, according to the statistical analysis and interviews, positive effects outweigh negative effects. Students acknowledged that these shortcomings mentioned above had negative effects on truth-seeking, analyticity and systematicity when they newly approached to the digital learning in their first college year. But throughout college years, a proper use of digital learning platforms is gradually on track, which in return, facilitates their desire for truth-seeking, inclination to be organized and focused, which refers to systematicity, and alertness to find out reason and evidence which refers to analyticity.

Although digital learning is found to be an impact on critical thinking disposition, it is not the only factor. The

TABLE I. DESCRIPTIVE ANALYSIS OF STUDENTS’ CRITICAL THINKING DiSPOSITIONS

\begin{tabular}{|c|c|c|c|c|c|c|c|}
\hline \multirow{2}{*}{$\begin{array}{c}\text { Class } \\
\text { Level }\end{array}$} & \multirow{2}{*}{ Mean } & \multirow{2}{*}{ Max. } & \multirow{2}{*}{ Min. } & \multicolumn{4}{|c|}{ Proportion } \\
\cline { 5 - 8 } & & & & Negative & Middle & Positive & Strong \\
\hline Seniors & 302.66 & 366 & 239 & 0 & $18.75 \%$ & $75.00 \%$ & $6.25 \%$ \\
\hline Freshmen & 286.35 & 342 & 231 & 0 & $35.48 \%$ & $64.52 \%$ & 0 \\
\hline
\end{tabular}

TABLE II. MEAN DIFFERENCES BETWEEN FRESHMEN AND SENIORS ON THE CTDI-CV

\begin{tabular}{|c|c|c|c|c|c|c|c|c|}
\hline \multirow{2}{*}{ CCTDI Scale } & \multicolumn{2}{|c|}{ Seniors $(n=32)$} & \multicolumn{2}{|c|}{ Freshmen $(n=31)$} & \multirow{2}{*}{$\begin{array}{c}\text { Mean } \\
\text { difference }\end{array}$} & \multirow{2}{*}{$\begin{array}{c}t \\
(61)\end{array}$} & \multirow{2}{*}{$p$} & \multirow{2}{*}{$\begin{array}{c}\text { Cohen's } \\
d\end{array}$} \\
\hline & Mean & $S D$ & Mean & $S D$ & & & & \\
\hline Truth-s eeking & 38.91 & 4.91 & 35.77 & 5.10 & 3.13 & 2.48 & $.016^{*}$ & 0.63 \\
\hline Open-mindedness & 41.94 & 4.63 & 41.58 & 5.41 & 0.36 & 0.28 & .779 & 0.07 \\
\hline Analyticity & 46.84 & 5.20 & 43.52 & 5.81 & 3.33 & 2.40 & $.020 *$ & 0.60 \\
\hline Systematicity & 41.34 & 6.21 & 38.58 & 4.71 & 2.76 & 1.99 & .052 & 0.50 \\
\hline Self-confidence & 43.00 & 4.95 & 39.97 & 6.00 & 3.03 & 2.19 & $.032 *$ & 0.55 \\
\hline Inquisitiveness & 47.84 & 5.93 & 45.29 & 6.23 & 2.55 & 1.67 & .100 & 0.41 \\
\hline Maturity & 42.03 & 6.37 & 40.61 & 6.63 & 1.42 & 0.87 & .390 & 0.22 \\
\hline CTD Overall & 302.66 & 30.47 & 286.35 & 26.94 & 16.30 & 2.25 & $.028^{*}$ & 0.57 \\
\hline
\end{tabular}


overall higher education makes contributions to students' critical thinking dispositions from many aspects besides digital learning, including academic programs, social activities, voluntary work, internship and so on. In addition, the process to learn English language is a process to learn exotic cultures and broaden the horizon, which may make a contribution to the characteristic of open-mindedness.

But it cannot be neglected that truth-seeking and systematicity are still relatively weaker even at the time of graduation indicating that the side effects of the digital learning still exist. Besides, the lack of truth-seeking and systematicity is college students' general shortcoming. When facing with findings which are not in accord with one's self-interest or preconceived ideas, students are less willing to seek the best solution objectively. When facing with complex tasks or abundant information, it is difficult to be focused, persistent and organized. Some previous studies have similar findings. These results are reflected by the weak truth-seeking in both freshmen and seniors [10] and the weak truth-seeking and systematicity showed in the distance education [6].

\section{CONCLUSION}

This study confirms the merits of digital learning. Providing broader access to more online educational resources proves to be a wise decision for universities and colleges. Practically, this study provides clues for designing and developing digital learning platforms and applications. Cultivating critical thinking dispositions should be set as an important design objective of digital learning. Among the subscale of the critical thinking disposition, truth-seeking and systematicity should be paid much more attention to.

Nevertheless, some limitations need to be considered. First, a larger sample size can be more representative. Second, further research into a more detailed change of the critical thinking disposition among four grades would be very interesting. Notwithstanding, it is believed that this study confirms the validity of digital learning applied in the higher education. The higher education and digital learning platforms are supposed to attach more importance to the cultivation of critical thinking dispositions.

\section{ACKNOWLEDGMENT}

Authors gratefully acknowledge the research support from the National Social Science Foundation of China (Ref. 12XYY012). Authors also would like to appreciate all the students participated in this research for their contributions and the anonymous reviewers for valuable comments on this paper.

\section{REFERENCES}

[1] P. Facione, Critical Thinking: What It Is and Why It Counts, Millbrae, CA: Measured Reasons and the Californ ia Academic Press, 2011, pp. 2 7.

[2] D. I. Ekici, "The effects of online communities of practice on preservice teachers' critical thinking dispositions," Eurasia Journal of Mathematics Science and Technology Education, vol. 13, pp. 7, July 2017.

[3] I. Yüksel, and E. Türkses, "Cross-sectional evaluation of distance education students' learning styles and critical thinking dispositions in turkey,” International Journal of Distance Education Technologies, vol. 13, pp. 70-86, January 2016.

[4] G. Siemens, "Connectivism: a learning theory for the digital age," International Journal of Instructional Technology \& Distance Learning, vol. 2, pp. 3-10, 2005.

[5] M. Clarà, \& E. Barberà, "Learning online: massive open online courses (moocs), connectivism, and cultural psychology,” Distance Education, vol. 34, pp. 129-136, June 2013.

[6] Z. Wang, T. Anderson, and L. Chen, "How learners participate in connectivist learning: an analysis of the interaction traces from a cmooc,” International Review of Research in Open \& Distance Learn ing, vol. 19, pp. 44-67, Feburary 2018.

[7] B. Aybek, “The relationship between prospective teachers' media and television literacy and their critical thinking dispositions," Eurasian Journal of Educational Research, vol. 16, pp. 261-278, 2016.

[8] M. Peng, G. Wang, J. Chen, M. Chen, H, Bai, S. Guo, et al., "Validity and reliability of the Chinese critical thinking disposition inventory," Chinese Journal of Nursing, vol. 39, pp. 644-647, 2004.

[9] T. Nie, \& J. Hu, "EFL Students' Satisfaction with the College English Education in the MOOC: An Empirical Study," Advances in Social Science, Education and Humanities Research, vol. 182, pp. 92-95, 2018.

[10] A. Alper, "Critical thinking disposition of pre-service teachers," Eğitim Ve Bilim, vol. 35, pp. 14-27, 2010. 